\title{
Understanding vascular pathoanatomy: Cinematic rendering of an abdominal aortic aneurysm treated with chimney endovascular aortic repair
}

\author{
Georg Hagleitner ${ }^{1, *}$, Peter Pichler ${ }^{1}$ and Franz A Fellner ${ }^{1,2}$ \\ ${ }^{1}$ Central Radiology Institute, Kepler University Hospital, Medical Faculty of the Johannes Kepler University, Linz, Austria \\ ${ }^{2}$ Medical Faculty of the Friedrich-Alexander-University of Erlangen-Nürnberg, Erlangen, Germany
}

\begin{abstract}
We present a case with an infrarenal AAA, treated with chimney endovascular aortic repair (CHEVAR) due to a strong inferior mesenteric artery (IMA). To enhance understanding of anatomy and pathoanatomy, pre- and postoperative cinematic rendered (CR) images were obtained from the patients' multidetector computed tomography (MDCT) datasets. We want to discuss possible applications for CR images to facilitate understanding of complex vascular pathologies and postprocedural conditions for medical professionals, students and the general public.
\end{abstract}

\section{Background}

CHEVAR has been established as a suitable option for the treatment of AAAs with involvement of the mesenteric or renal arteries. In this procedure, the perfusion of the target vessels is maintained through stent grafts laying alongside with a main graft tube. There are two main techniques in CHEVAR: the snorkel technique, where the blood flow is maintained antegrade from the proximal end of the main body stent graft to the target vessel, and the periscope technique, where the blood flow is secured in a retrograde fashion from the distal end of the main body stent graft to the target vessel. An alternative to CHEVAR is the fenestrated endovascular aortic repair (FEVAR), where the blood flow to the involved visceral and/or renal vessels is maintained through the implantation of stent grafts in individually designed and manufactured fenestrations in the main body stent graft [1-3].

An advantage of CHEVAR over FEVAR is, that there is no need for individually designed stent grafts. Thus, CHEVAR can also be used in emergency settings and in situations with challenging vascular pathoanatomy, where FEVAR is not possible. CHEVAR may also result in lower procedural costs. On the other hand, FEVAR delivers better long-term results and is associated with a lower rate of reinterventions $[1,2,4,5]$.

In the demonstration of vascular pathologies, it can be challenging for non-radiologists to understand complex problems and posttherapeutic conditions based on cross-sectional images alone. In this field, CR has emerged as a useful technology to facilitate the understanding of complex anatomical and pathoanatomical particularities and to illustrate post-therapeutic conditions [6-18]. CR images are photorealistic 3D reconstructions of cross-sectional images. To achieve this photorealistic effect, complex light and shadow models, taken from the production of animation trick films, are used. Meaningful CR images can be used to facilitate understanding in interdisciplinary conferences, for teaching and for the general public [6-18].

\section{Case report}

We present a case of a 81 year old male patient, who was diagnosed with a saccular infrarenal AAA. As a complicating anatomic feature, a strong IMA was present. An additional finding was a significant soft plaque stenosis of the left renal artery. Due to the eccentric saccular configuration of the aneurysm and the strong IMA, indication for CHEVAR with snorkel technique was made.

For the procedure, decision for a biinguinal retrograde access and an open retrograde trans brachial access from the left arm was made.

After cannulation of the left renal artery via the right inguinal access, the soft plaque stenosis of the left renal artery was treated with a covered stent (Advanta, Getinge, Sweden). To facilitate optimal placement of the main body stent graft and the chimney stent grafts, a $5 \mathrm{~F}$ pigtail diagnostic catheter was placed in the infrarenal aorta from the right inguinal access. Next, the IMA was cannulated over the brachial access with a 5F Berenstein (Cordis Inc., USA) catheter and a 0,035 " hydrophilic guidewire (Terumo Corp., Japan), which was then exchanged for a stiff 0,035 " guidewire (Amplatz Super Stiff, Boston Scientific, USA). The main body stent graft (Endurant II, Medtronic Inc., USA) was inserted over the left inguinal access over a stiff 0,035 " guidewire (Amplatz Super Stiff, Boston Scientific, USA). Subsequently, stenting of the IMA was performed with a covered stent graft (VBX, W.L. Gore \& Associates Inc., USA). To form the chimney, another covered stent graft (VBX, W.L. Gore \& Associates Inc., USA)

*Correspondence to: Georg Hagleitner, Central Radiology Institute, Kepler University Hospital, Medical Faculty of the Johannes Kepler University, Linz, Austria, E-mail: georg.hagleitner@kepleruniklinikum.at

Key words: cinematic rendering, interventional radiology, abdominal aortic aneurysm, chimney endovascular, aortic repair

Received: August 30, 2020; Accepted: September 25, 2020; Published: September 29, 2020 


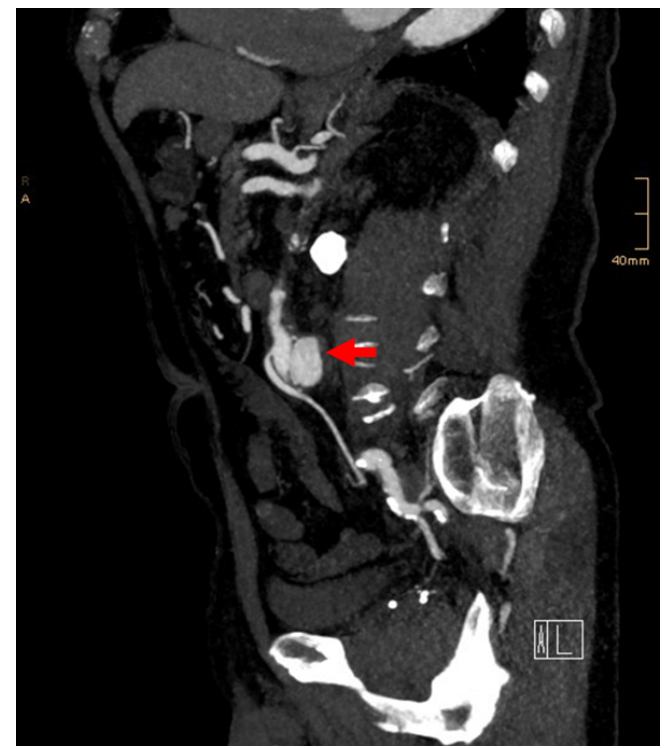

Figure 1. Preoperative sagittal maximum intensity projection (MIP) reconstruction from MDCT data depicting the saccular configuration of the aneurysm (arrow) and its relation to the IMA arising ventrally

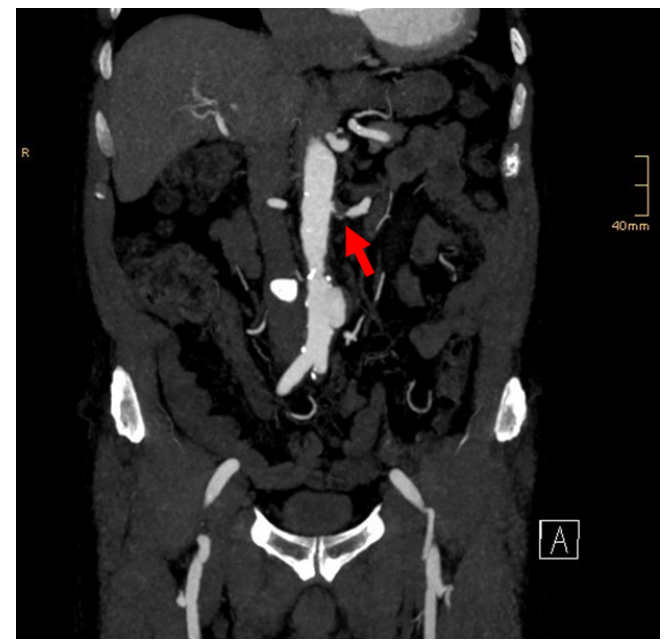

Figure 2. Preoperative coronal MIP image. Soft plaque stenosis of the left renal artery (arrow). Infrarenal saccular aneurysm with a long proximal landing zone

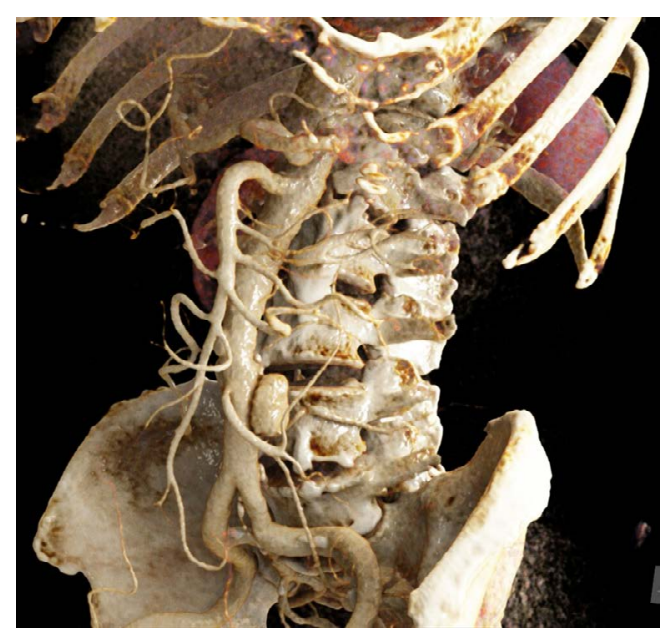

Figure 3. CR image obtained from preoperative MDCT data. Clear illustration of the saccular configuration of the aneurysm sac and its relation to the IMA, the renal arteries and the aortic bifurcation

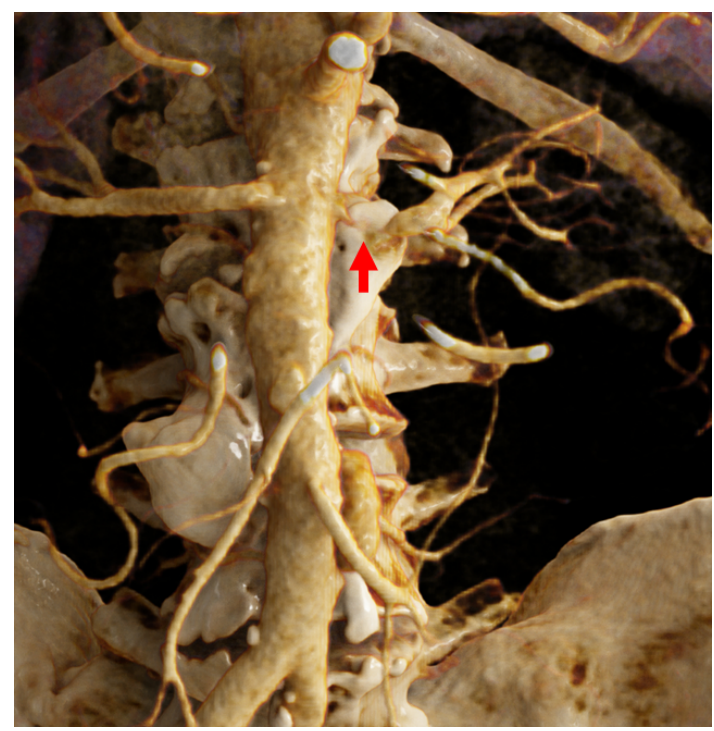

Figure 4. CR image from preoperative MDCT data. High grade stenosis of the left renal artery, strong IMA in relation to the aneurysmatic sac

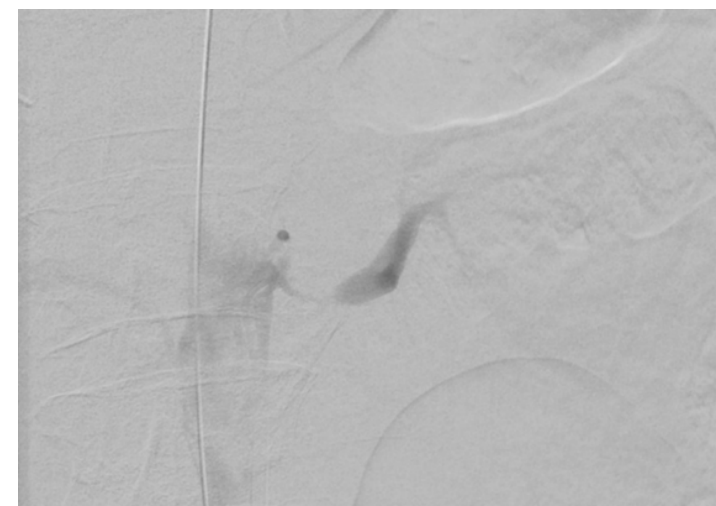

Figure 5. Intraoperative angiogram of the left renal artery confirms the significant stenosis

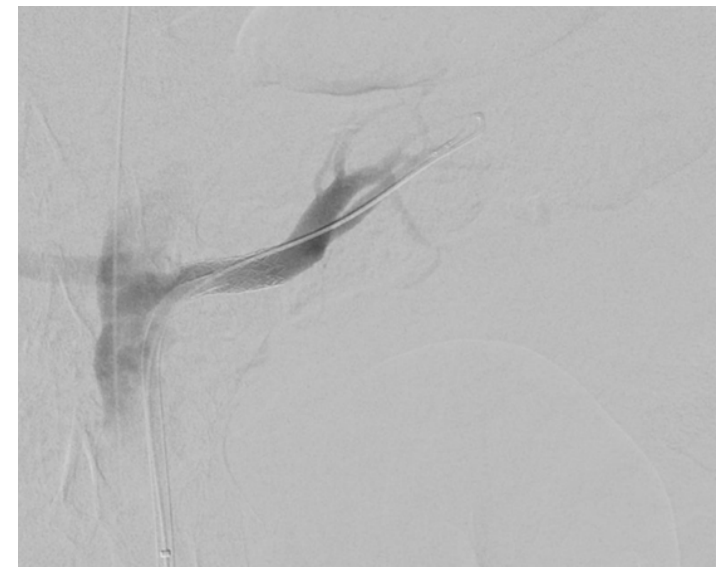

Figure 6. Check angiogram after placement of a covered stent in the left renal artery 


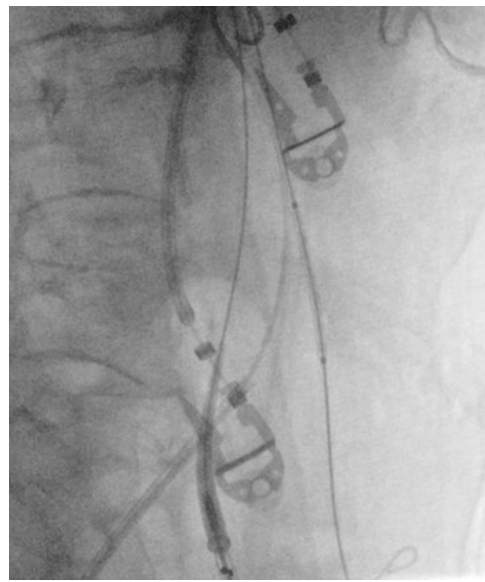

Figure 7. Right anterior oblique (RAO) view. Placement of the first covered stent in the IMA from the left brachial access. Note the main body stent graft from the left inguinal access, ready for placement

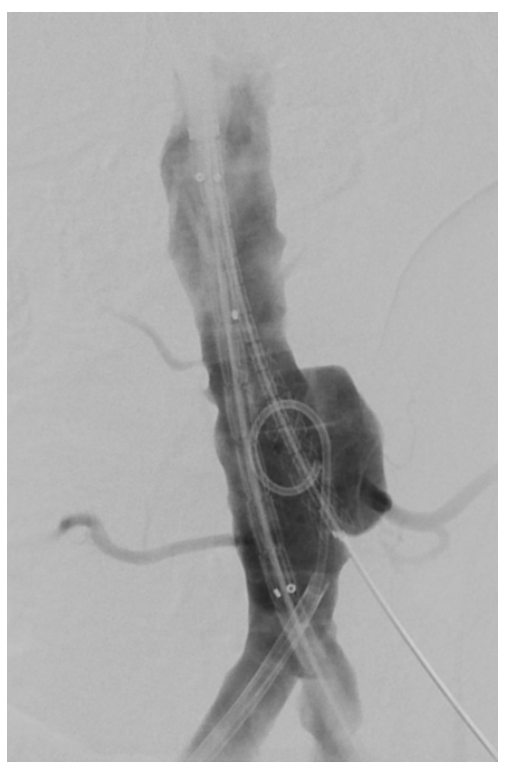

Figure 8. Deployed stent graft in the proximal IMA. Placement of the main body stent graft and the second chimney stent graft. Note the saccular configuration of the aneurysm

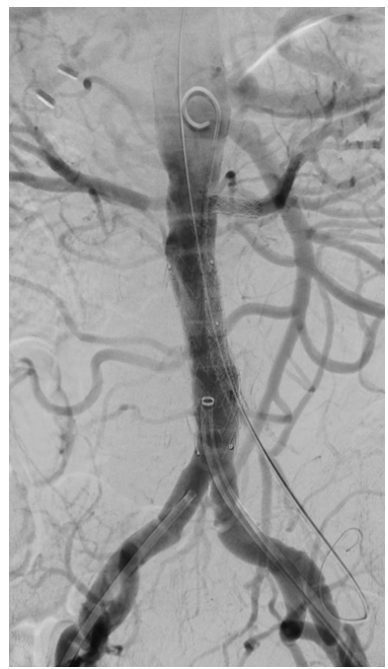

Figure 9. Final angiogram shows good stent graft placement. Intentional placing of the chimney stent graft higher than the proximal end of the main body stent graft to avoid development of type Ia endoleak

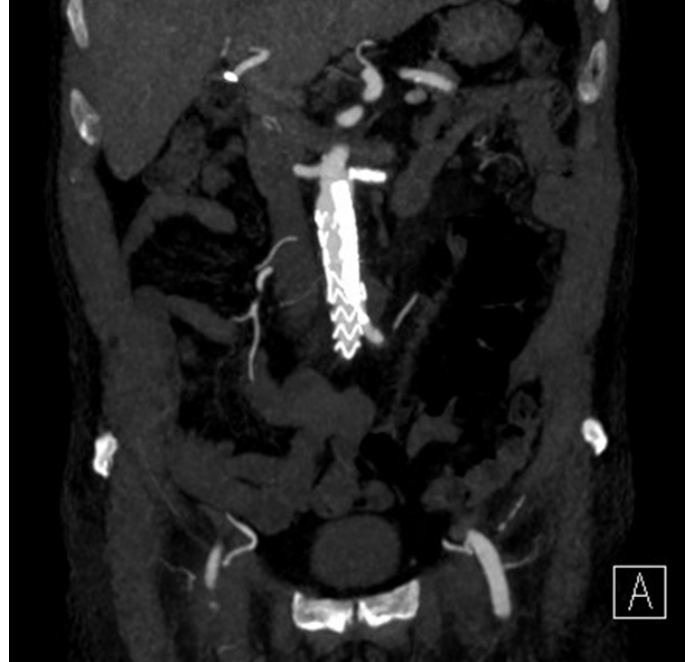

Figure 10. Postoperative CT, coronal MIP image. Good chimney placement. Note the sten graft in the left renal artery

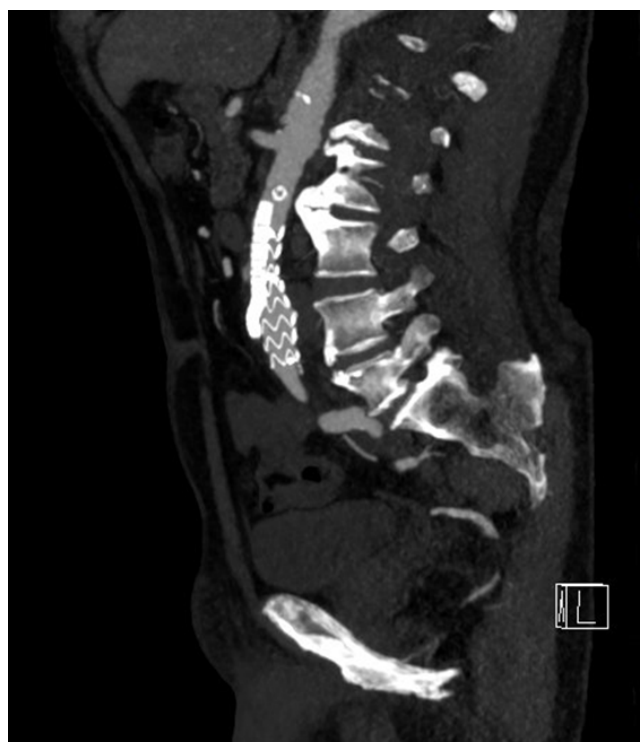

Figure 11. Postoperative CT, sagittal MIP image. Good chimney placement. Note the stent graft in the left renal artery

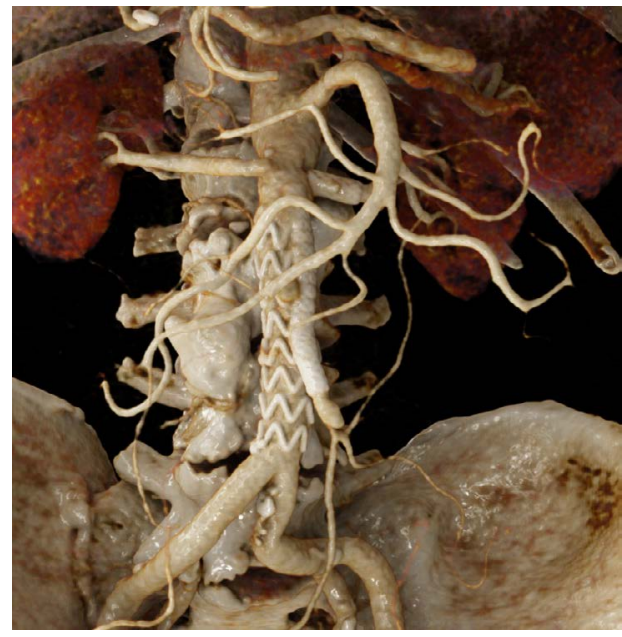

Figure 12. CR image from postoperate MDCT. Meaningful illustration of the CHEVAR and the stent graft in the left renal artery at one glance 
was inserted from the brachial access. During partial detachment of the main body stent graft the second chimney stent graft was carefully inflated at a low-pressure level. Then the main body stent graft was then fully deployed from the delivery system, which was then exchanged for a compliant balloon (Reliant, Medtronic Inc., USA). As a final step, the main body stent graft was molded to the aortic wall with full inflation of the chimney stent graft to facilitate sealing of the treated aortic section.

Final angiogram showed good placing of the stent grafts, preserved blood flow to the left kidney and IMA as well as to the iliac arteries, and no relevant endoleak. Postoperative course was uneventful. The first follow-up MDCT scan on the seventh postoperative day showed no early complications and good stent graft placement.

\section{Discussion}

Several authors have proposed a more aggressive therapeutic approach towards saccular aortic aneurysms, since the rupture risk is higher than in fusiform aneurysm sac, as they become acute earlier at smaller diameters. This might be associated with their etiology, which includes penetrating atherosclerotic ulcer, infection or trauma of the aorta, and previous aortic surgery $[19,20]$. In the presented case, penetrating atherosclerotic ulcer of the infrarenal abdominal aorta was suspected, which led to the indication of an EVAR. As colon ischemia is associated with an increased mortality rate, decision for preservation of the strong IMA through CHEVAR was made [19-21].

In aortic and vascular diseases, it can be challenging to understand pre- and post-therapeutic anatomical and pathoanatomical particularities. As shown in the images above, it is much easier to understand the main pathology and the postoperative condition with meaningful and often self-explaining CR images. In interdisciplinary discussions, in the planning phase of a procedure, during the informed consent discussion with the patient, when teaching medical and healthcare students and when educating the general public, it can be helpful to use photorealistic CR images to facilitate understanding of such complex pathologies and post-therapeutic conditions [6-18].

\section{Conclusion}

CHEVAR is an established procedure for endovascular repair of AAAs involving the visceral vessels, especially in emergency situations and when a challenging anatomy is present. CR can facilitate understanding of complex problems for medical professionals, medical and health-care students and medical lay persons.

\section{Disclosure}

No conflicts of interest. No grants or financial supports.

\section{References}

1. Kansagra K, Kang J, Taon MC, Ganguli S, Gandhi R, et al. (2018) Advanced endografting techniques: snorkels, chimneys, periscopes, fenestrations, and branched endografts. Cardiovasc Diagn Ther 8(Suppl): 175-183. [Crossref]
2. Wanhainen A, Verzini F, van Herzeele I, Allaire E, Bown M, et al. (2019) European Society for Vascular Surgery (ESVS) 2019 Clinical Practice Guidelines on the Management of Abdominal Aorto-iliac Artery Aneurysms. Eur J Vasc Endovasc Surg 57: 8-93. [Crossref]

3. Koncar IB, Jovanovic AL, Ducic SM (2020) The role of fEVAR, chEVAR and open repair in treatment of juxtarenal aneurysms: a systematic review. J Cardiovasc Surg 61(1): 24-36. [Crossref]

4. Swerdlow NJ, Wu WW, Schermerhorn ML (2019) Open and Endovascular Management of Aortic Aneurysms. Circ Res 124: 647-661. [Crossref]

5. Taneva GT, Donas KP, Pitoulias GA, Austermann M, Veith FJ, Torsello G (2020) Costeffectiveness analysis of chimney/snorkel versus fenestrated endovascular repair for high-risk patients with complex abdominal aortic pathologies. J Cardiovasc Surg 61(1): 18-23. [Crossref]

6. Fellner FA(2016) Introducing cinematic rendering: Anovel technique for postprocessing medical imaging data. J Biomedical Science and Engineering 9: 170-175.

7. Fellner FA, Berger F, Fellner C, Kremer C, Hortner H, et al. (2016) Volume rendering of medical imaging data for the general public. J Health Med Informat 7: 213.

8. Binder J, Krautz C, Engel K, Grützmann R, Fellner FA, et al. (2019) Leveraging medical imaging for medical education - a cinematic rendering-featured lecture. Ann Anat 222: 159-165. [Crossref]

9. Elshafei M, Binder J, Baecker J, Brunner M (2019) Comparison of Cinematic Rendering and Computed Tomography for Speed and Comprehension of Surgical Anatomy. JAMA Surg 154(8): 738-744. [Crossref]

10. Hofko M, Sonnberger M, Fellner FA (2020) Cerebral dural arterio-venous fistula - Part I: Virtual anatomy and pathoanatomy in CT and MR imaging. Trauma Emerg Care 5.

11. Stehrer R, Malek M, Fellner FA (2020) Cinematic Rendering for virtual anatomy and pathoanatomy in cranio-maxillofacial trauma care. Trauma Emerg Care 5.

12. Derler V, Fellner FA (2020) Virtual anatomy and pathoanatomy - subluxation fracture of the cervical spine. Glob Imaging Insights 5.

13. Firmötz A, Fellner FA (2020) Virtual anatomy and pathoanatomy: Cinematic Rendering of a proximal humerus fracture. Glob Imaging Insights 5 .

14. Asel C, Malek M, Fellner FA (2018) Preoperative cinematic rendering of a sinus frontalis frontal bone fracture. Glob Imaging Insights 3 .

15. Hagleitner G, Fellner FA (2017) Ossicle vs. avulsion fracture: Cinematic rendering of MDCT data as an additional diagnostic key. Glob Imaging Insights 2.

16. Akbari K, Fellner CM, Fellner FA (2017) Rare case of an aneurysmal bone cyst oft he skull. Glob Imaging Insights 2.

17. Fellner FA, Behawy M (2017) Cinematic and volume rendering of a scaphoid fracture. Glob Imaging Insights 2.

18. Fellner FA (2016) "Cinematic Rendering" of an Egyptian fish mummy with a fractured spinal column. Glob Imaging Insights 2.

19. Karthaus EG, Tong TML, Vahl A, Hamming JF (2019) Saccular Abdominal Aortic Aneurysms. Annals of Surgery 270(5): 852-858.

20. Shang EK, Nathan DP, Boonn WW, Lys-Dobradin IA, Fairman RM, et al. (2013) A modern experience with saccular aortic aneurysms. J Vasc Surg 57(1): 84-88.

21. Williamson JS, Ambler GK, Twine CP, Williams IM, Williams GL (2018) Elective Repair of Abdominal Aortic Aneurysm and the Risk of Colonic Ischaemia: Systematic Review and Meta-Analysis. Eur J Vasc Endovasc Surg 56: 31-39.

Copyright: $\odot 2020$ Hagleitner G. This is an open-access article distributed under the terms of the Creative Commons Attribution License, which permits unrestricted use, distribution, and reproduction in any medium, provided the original author and source are credited. 